\title{
ДВУМЕРНАЯ МОДЕЛЬ ПРОЦЕССА ГАЗИФИКАЦИИ ТВЕРДОГО ТОПЛИВА В НЕПОДВИЖНОМ СЛОЕ ПОД ДАВЛЕНИЕМ \\ 2. ЧИСЛЕННЫЕ РЕЗУЛЬТАТЫ ТЕРМОХИМИЧЕСКОЙ ПЕРЕРАБОТКИ ШУБАРКОЛЬСКОГО КАМЕННОГО УГЛЯ ПРИ ОТНОШЕНИИ МАССОВЫХ ДОЛЕЙ $\mathrm{H}_{2} \mathrm{O} / \mathrm{O}_{2}=72 / 28$
}

\author{
Б.Б. Рохман, докт. техн. наук \\ Институт угольных энерготехнологий НАН Украины, \\ 04070, г. Киев, ул. Андреевская 19
}

\begin{abstract}
С использованием разработанной двумерной модели, приведенной в первой части настоящей работы, которая включает в себя межфазный конвективный теплообмен, радиационно-кондуктивный теплоперенос твердой фазы, лучистый и кондуктивный теплообмен неподвижного слоя со стенкой реактора, гетерогенные и гомогенные химические реакиии, силь тяжести и аэродинамического сопротивления численно исследован нестационарный процесс газификации шубаркольского каменного длиннопламенного угля в парокислородной смеси под давлением 3 МПа в неподвижном слое с твердым шлакоудалением при отношении массовых долей газовых компонентов $\mathrm{H}_{2} \mathrm{O} / \mathrm{O}_{2}=72 / 28$. Показано, что: 1) в рассматриваемом режиме температура коксозольных частии не превышает $1000{ }^{\circ} \mathrm{C}$ за счет превалирования тепловыделения экзотермических реакиий $\mathrm{C}+\mathrm{O}_{2}=\mathrm{CO}_{2}, \mathrm{C}+0,5 \mathrm{O}_{2}=\mathrm{CO}, \mathrm{CO}+0,5 \mathrm{O}_{2}=\mathrm{CO}_{2}$ и $\mathrm{H}_{2}+0,5 \mathrm{O}_{2}=\mathrm{H}_{2} \mathrm{O}$ над теплопоглощением эндотермических реакиий $\mathrm{C}+\mathrm{CO}_{2}=2 \mathrm{CO}$ и $\mathrm{C}+\mathrm{H}_{2} \mathrm{O}=\mathrm{CO}+\mathrm{H}_{2}$ из-за большой концентрации водяных паров в газовой смеси. Поэтому генераторный газ по своим характеристикам калорийности и качеству (в момент времени $\tau=260 \mathrm{c}$ (по объему): $\mathrm{CO}=16,4 \%, \mathrm{H}_{2}=44,6 \%$, $\mathrm{CO}_{2}=27,6 \%, \mathrm{CH}_{4}=10,1 \%$ и $\left.\mathrm{C}_{6} \mathrm{H}_{6}=1,16 \%\right)$ значительно уступает синтетическому газу, полученному при отномении массовых долей газовых компонентов $\mathrm{H}_{2} \mathrm{O} / \mathrm{O}_{2}=40 / 60$ ( $\tau=280 \mathrm{c}: \mathrm{CO}=65 \%, \mathrm{H}_{2}=25,6 \%, \mathrm{CO}_{2}=3,8 \%, \mathrm{CH}_{4}=5 \%$ u $\mathrm{C}_{6} \mathrm{H}_{6}=0,57 \%$ ) [1]; 2) для устранения перегрева колосников из-за низкой высоты шлаковой подушки, обусловленной малой зольностью угля $3-$ 9\%, в исходное топливо рекомендуется добавлять отработанную золу, что позволит повысить высоту зашитного инертного слоя; 3) расчетный состав синтетического газа при $\tau=260$ с хорошо согласуется с литературными данными, приведенными в [2]: $\mathrm{CO}=12-21 \%, \mathrm{H}_{2}=37-41 \%, \mathrm{CO}_{2}=27-34 \%$ и $\mathrm{CH}_{4}=10-13,5 \%$. Библ. 2, рис. 7.
\end{abstract}

Ключевые слова: неподвижный слой, уголь, парокислородная газификация, конвективный, кондуктивный, радиационный, температура

\section{TWO-DIMENSIONAL MODEL OF THE SOLID FUEL GASIFICATION IN A FIXED BED UNDER PRESSER.}

\section{NUMERICAL RESULTS OF THERMAL-CHEMICAL PROCESSING OF SHUBARKOL COAL AT A RATIO OF MASS FRACTIONS H2O/O2=72/28.}

B. Rokhman, doctor of technical sciences

Coal Energy Technology Institute NAS of Ukraine,

04070, Kyiv, ul. Andreevskaya 19

With the help of the developed two-dimensional model presented in the first part of this work, which includes interfacial convective heat transfer, radiation-conductive heat transfer of the solid phase, radiant and conductive heat transfer of the fixed bed with the reactor wall, heterogeneous and homogeneous chemical reactions, gravity and aerodynamic resistance, the non-stationary gasification of Shubarkol long-flame coal in a steam-oxygen mixture under a pressure of $3 \mathrm{MPa}$ in a fixed bed with solid slag removal at a ratio of mass fractions of gas components $\mathrm{H}_{2} \mathrm{O} / \mathrm{O}_{2}=72 / 28$ was numerically investigated. It is shown: 1) in this mode, the temperature of coke-ash particles does not exceed $1000{ }^{\circ} \mathrm{C}$ due to the prevalence of heat generation of exothermic reactions $\mathrm{C}+\mathrm{O}_{2}=\mathrm{CO}_{2}$, $\mathrm{C}+0,5 \mathrm{O}_{2}=\mathrm{CO}, \mathrm{CO}+0,5 \mathrm{O}_{2}=\mathrm{CO}_{2}$ and $\mathrm{H}_{2}+0,5 \mathrm{O}_{2}=\mathrm{H}_{2} \mathrm{O}$ over the heat absorption of endothermic reactions $\mathrm{C}+\mathrm{CO}=2 \mathrm{CO}$ and $\mathrm{C}+\mathrm{H}_{2} \mathrm{O}=\mathrm{CO}+\mathrm{H}_{2}$ due to the high concentration of water vapor in the gas mixture. Therefore, calorie and quality of the generator gas (at the time $\tau=260 \mathrm{~s}$ (by volume): $\mathrm{CO}=16,4 \%, \mathrm{H}_{2}=44,6 \%, \mathrm{CO}_{2}=27,6 \%, \mathrm{CH}_{4}=10,1 \%$ and $\mathrm{C}_{6} \mathrm{H}_{6}=1,16 \%$ ) is significantly inferior to the synthetic gas obtained with the ratio of mass fractions of gaseous components $\mathrm{H}_{2} \mathrm{O} / \mathrm{O}_{2}=40 / 60$ ( $\tau=280 \mathrm{c}: \mathrm{CO}=65 \%, \mathrm{H}_{2}=25,6 \%$, $\mathrm{CO}_{2}=3,8 \%, \mathrm{CH}_{4}=5 \%$ and $\mathrm{C}_{6} \mathrm{H}_{6}=0,57 \%$ ) [1];2) To eliminate overheating of the grate due to the low height of the slag pad, due to low ash content of coal 3-9\%, it is recommended to add waste ash to the initial fuel, which will increase the height of the protective inert bed. 3) the calculated composition of the synthetic gas at $\tau=260 \mathrm{~s}$ is in good agreement with the literature data given in [2]: $\mathrm{CO}=12-21 \%, \mathrm{H}_{2}=37-41 \%, \mathrm{CO}_{2}=27-34 \%$ and $\mathrm{CH}_{4}=10-13,5 \%$.

Keywords: fixed bed, coal, thermal conductivity, steam-oxygen gasification, conductive, radiation, temperature 


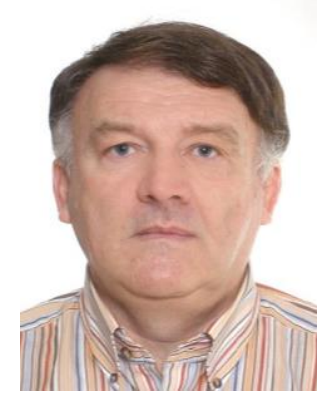

Б.Б. Рохман

B. Rokhman
Сведения об авторе: ведущий научный сотрудник Института угольных энерготехнологий НАН Украины, доктор технических наук. Биографические данные Рохмана Б.Б. размещены в известных мировых изданиях "Who's Who in Science and Engineering" и "2000 Outstanding Intellectuals of the 21st Century".

Образование: Новочеркасский политехнический институт.

Научная сфера: Математическое моделирование аэро-динамики, тепломассообмена и химического реагирования поли-дисперсного ансамбля твердого топлива в камерных и слоевых топках, в реакторах с циркулирующим кипящим слоем и в кипящем слое.

Публикации: более 90 научных работ, из них 27 работ содержатся в наукометрической базе Scopus и 4 в наукометрической базе Web of Science.

ORCID: 0000-0002-1270-6102

Контакты: тел.: +38-044-425-53-77

e-mail: Brolene@yahoo.com
Information about the author: the leading researcher of the Institute of Coal Energy Technologies of the NAS of Ukraine, Doctor of Technical Sciences. Biographical information of Rohman B.B. is published in wellknown world directories "Who's Who in Science and Engineering" and "2000 Outstanding Intellectuals of the 21st Century".

Education: Novocherkassk Polytechnic Institute.

Research area: Mathematical modeling of aerodynamics, heat and mass transfer and chemical reaction of a polydisperse ensemble of solid fuel in chamber and layer furnaces, in reactors with a circulating fluidized bed and in the fluidized bed.

Publications: more than 90 scientific papers, 27 of them are contained in the science-based Scopus database and 4 in the science-based Web of Science database.

ORCID: 0000-0002-1270-6102

Contacts: phone: $+38-044-425-53-77$

e-mail: Brolene@yahoo.com
В работе [1] описаны двумерная модель и теоретические исследования нестационарного процесса парокислородной газификации частиц шубаркольского каменного длиннопламенного угля под давлением 3 Мпа в неподвижном слое при отношении $\mathrm{H}_{2} \mathrm{O} / \mathrm{O}_{2}=45 / 55$. Показана возможность организации рабочего процесса в газогенераторе с устойчивым жидким шлакоудалением при $\mathrm{H}_{2} \mathrm{O} / \mathrm{O}_{2}=40 / 60$ и максимальной температуре частиц $1550{ }^{\circ} \mathrm{C}$ в малой области, прилегающей к решетке. Состав полученного генераторного газа при $\mathrm{H}_{2} \mathrm{O} / \mathrm{O}_{2}=45 / 55$ и при $\mathrm{H}_{2} \mathrm{O} / \mathrm{O}_{2}=40 / 60$ хорошо согласуется с литературными данными, а его калорийность оказывается выше, чем при газификации угольной пыли в потоке.

Во второй части настоящей работы рассматривается нестационарный процесс парокислородной газификации дробленных частиц шубаркольского каменного угля размером 9 мм и

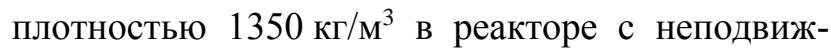
ным слоем порозностью 0,4 , высотой слоя 2,75 м и сечением $0,5 \mathrm{~m}^{2}$ под давлением $P_{\mathrm{g}}=3$ Мпа с твердым шлакоудалением при отношении $\mathrm{H}_{2} \mathrm{O} / \mathrm{O}_{2}=72 / 28\left(B_{\mathrm{H}_{2} \mathrm{O}}=1991 \kappa г / ч, B_{\mathrm{O}_{2}}=774\right.$ кг/ч и $t_{\mathrm{H}_{2} \mathrm{O}+\mathrm{O}_{2}}=450{ }^{\circ} \mathrm{C}$ ), когда температура частиц в окислительной зоне не превышает $1000{ }^{\circ} \mathrm{C}$.

Как отмечалось в работе [1], в соответствии с изменениями, претерпеваемыми топливом на различных стадиях термохимической переработки, неподвижный слой угля в реакторе можно условно разделить на четыре зоны: 1 - шлаковая подушка, 2 - зона окисления, 3 - зона газификации и 4 - зона сухой перегонки. Окислительную зону $0,031 \mathrm{~m}<z<0,0704$ м можно условно разделить на два характерных диапазона. В первом из них $0,031 \mathrm{~m}<z<0,039$ м происходит резкое возрастание температуры коксозольных частиц $t_{\mathrm{p}} \mathrm{c}$ $450{ }^{\circ} \mathrm{C}$ до максимального значения $991{ }^{\circ} \mathrm{C}$ за счет превалирования тепловыделения экзотермических реакций $\mathrm{C}+\mathrm{O}_{2}=\mathrm{CO}_{2}, \quad \mathrm{C}+0,5 \mathrm{O}_{2}=\mathrm{CO}$, $\mathrm{CO}+0,5 \mathrm{O}_{2}=\mathrm{CO}_{2}$ и $\mathrm{H}_{2}+0,5 \mathrm{O}_{2}=\mathrm{H}_{2} \mathrm{O}$ над теплопоглощением эндотермических реакций $\mathrm{C}+\mathrm{CO}_{2}=2 \mathrm{CO}$ и $\mathrm{C}+\mathrm{H}_{2} \mathrm{O}=\mathrm{CO}+\mathrm{H}_{2}$ (рис. 1, кривая 2). В результате содержание $\mathrm{O}_{2}$ и $\mathrm{H}_{2} \mathrm{O}$ в газовой смеси падает с 17,9\% и $82 \%$ до $14,3 \%$ и $74,3 \%$, соответственно, объемные доли газовых компонентов $\mathrm{CO}_{2}, \mathrm{CO}$ и $\mathrm{H}_{2}$ повышаются и достигают следующих значений: $R_{\mathrm{CO}}=5,8 \%, R_{\mathrm{H}_{2}}=3,79 \%$, $R_{\mathrm{CO}_{2}}=1,83 \%$ (рис. $2 a$, рис. 3 , рис. 4 , кривые 2 ). 


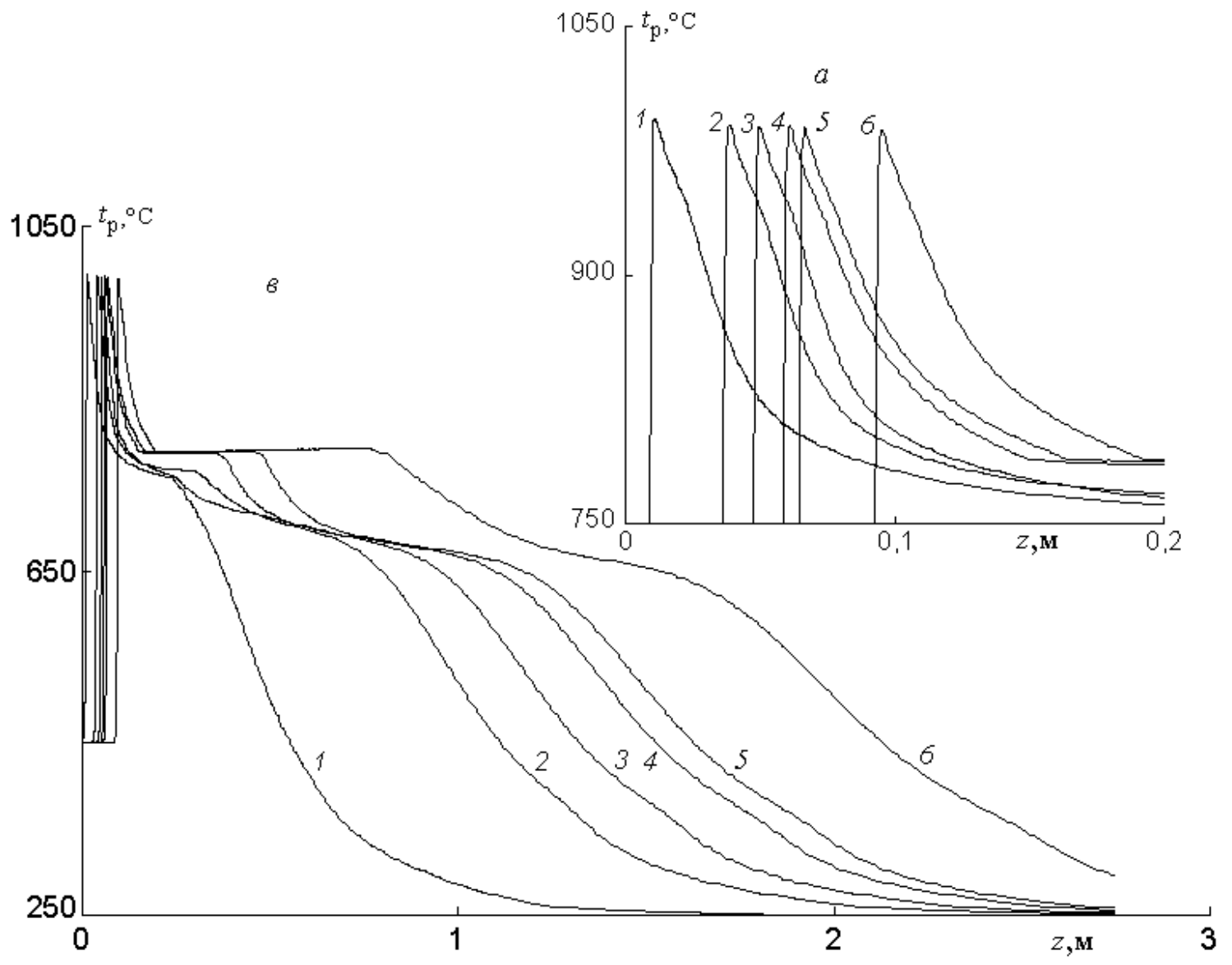

Рис. 1. Распределение температуры частиц по высоте неподвижного слоя в зависимости от времени: $1-60$ c; 2 - 160 c; $3-200$ c; $4-240$ c; $5-260$ c; $6-360$ c

Fig. 1. Temperature distribution of particles along the height of the fixed bed depending on time: $1-60 \mathrm{~s} ; 2-160 \mathrm{~s} ; 3-200 \mathrm{~s}$; $4-240 \mathrm{~s} ; 5-260 \mathrm{~s} ; 6-360 \mathrm{~s}$
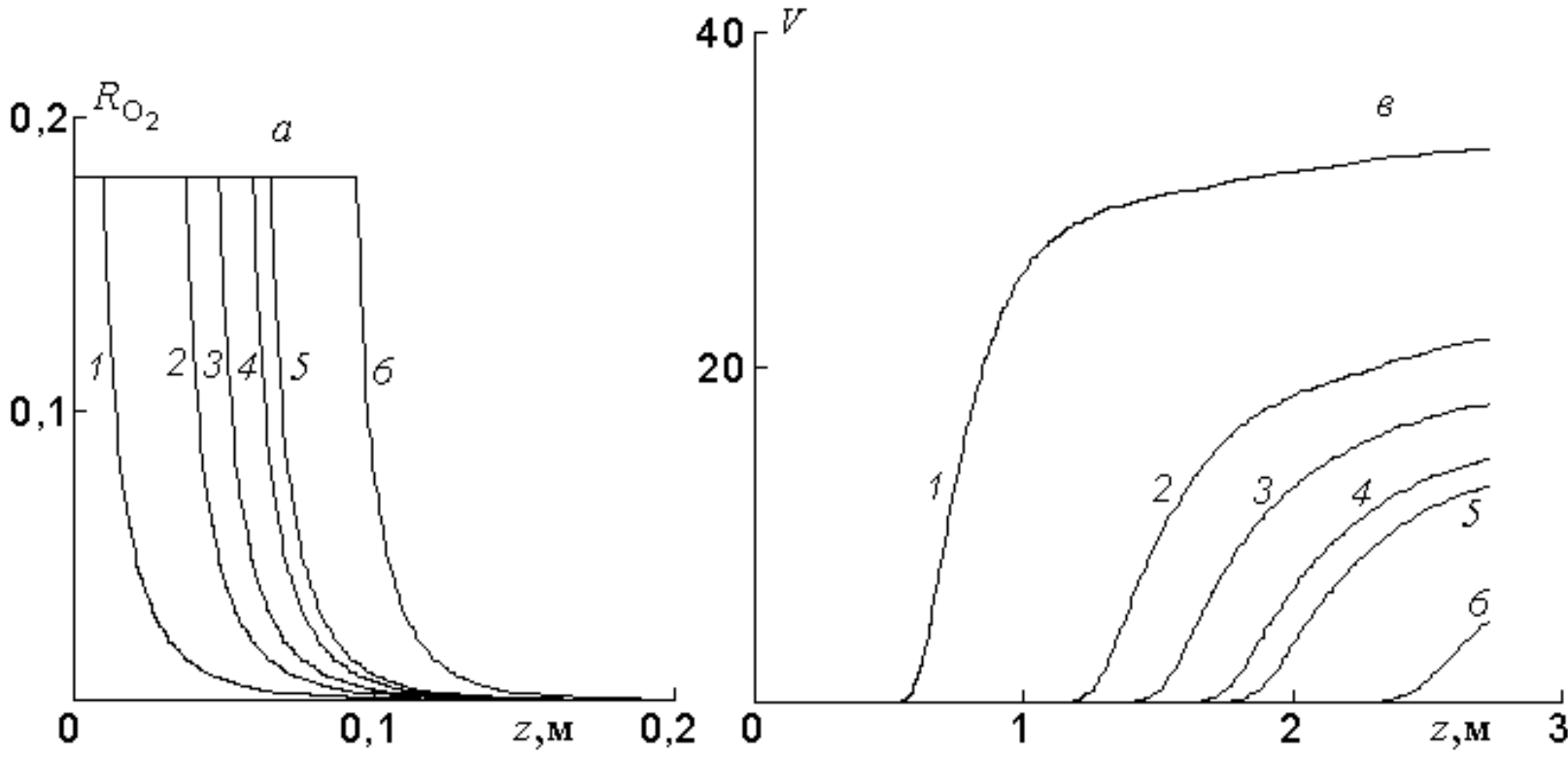

Рис. 2. Распределение объемной доли кислорода (a) и летучих веществ (в) по высоте неподвижного слоя в зависимости от времени (обозначения те же, что на рис. 1)

Fig. 2. Distribution of the volume fraction of oxygen $(a)$ and volatile substances $(b)$ over the height of the fixed bed depending on time (notations are the same as in Fig. 1) 

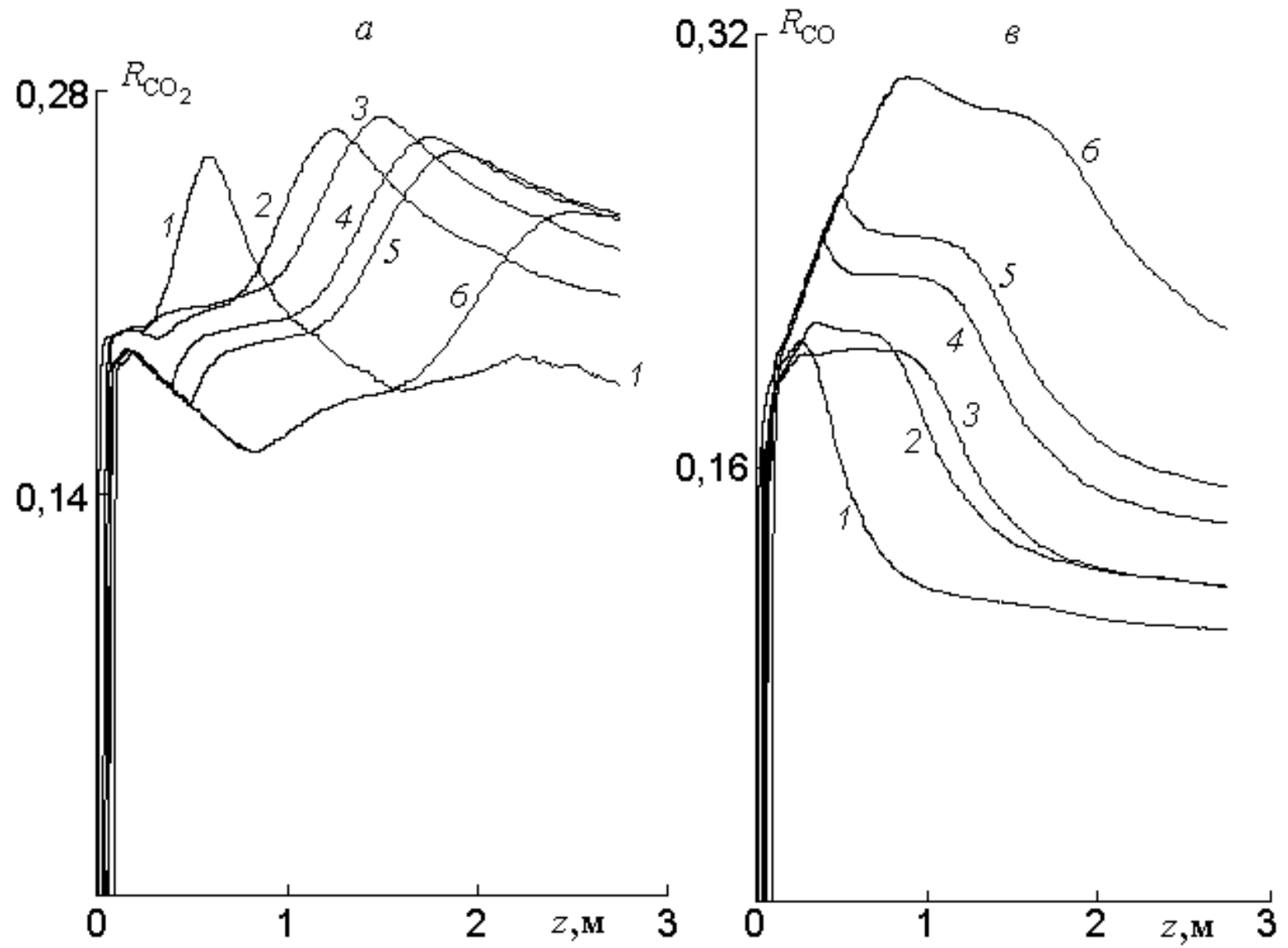

Рис. 3. Распределение объемных долей компонентов газа $\mathrm{CO}_{2}(a)$ и СО (в) по высоте неподвижного слоя в зависимости от времени (обозначения те же, что на рис. 1)

Fig. 3. Distribution of volume fractions of gas components $\mathrm{CO}_{2}(a)$ and $\mathrm{CO}(\boldsymbol{b})$ over the height of the fixed bed depending on time (notations are the same as in Fig. 1)
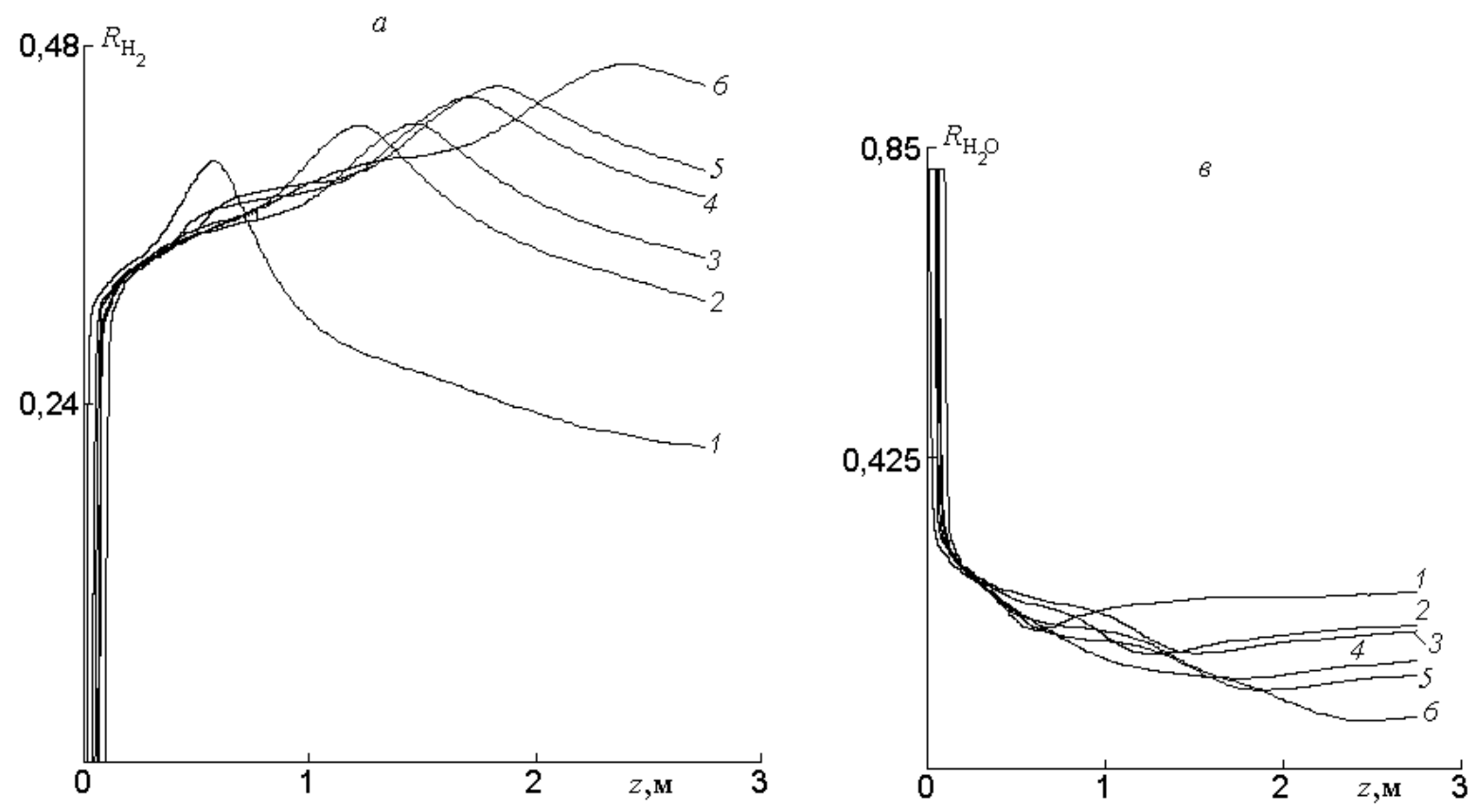

Рис. 4. Распределение объемных долей компонентов газа Н2 (a) и Н2О (в) по высоте неподвижного слоя в зависимости от времени (обозначения те же, что на рис. 1)

Fig. 4. Distribution of volume fractions of gas components $\mathrm{H}_{2}(a)$ and $\mathrm{H}_{2} \mathrm{O}($ (b) over the height of the fixed bed depending on time (notations are the same as in Fig. 1) 


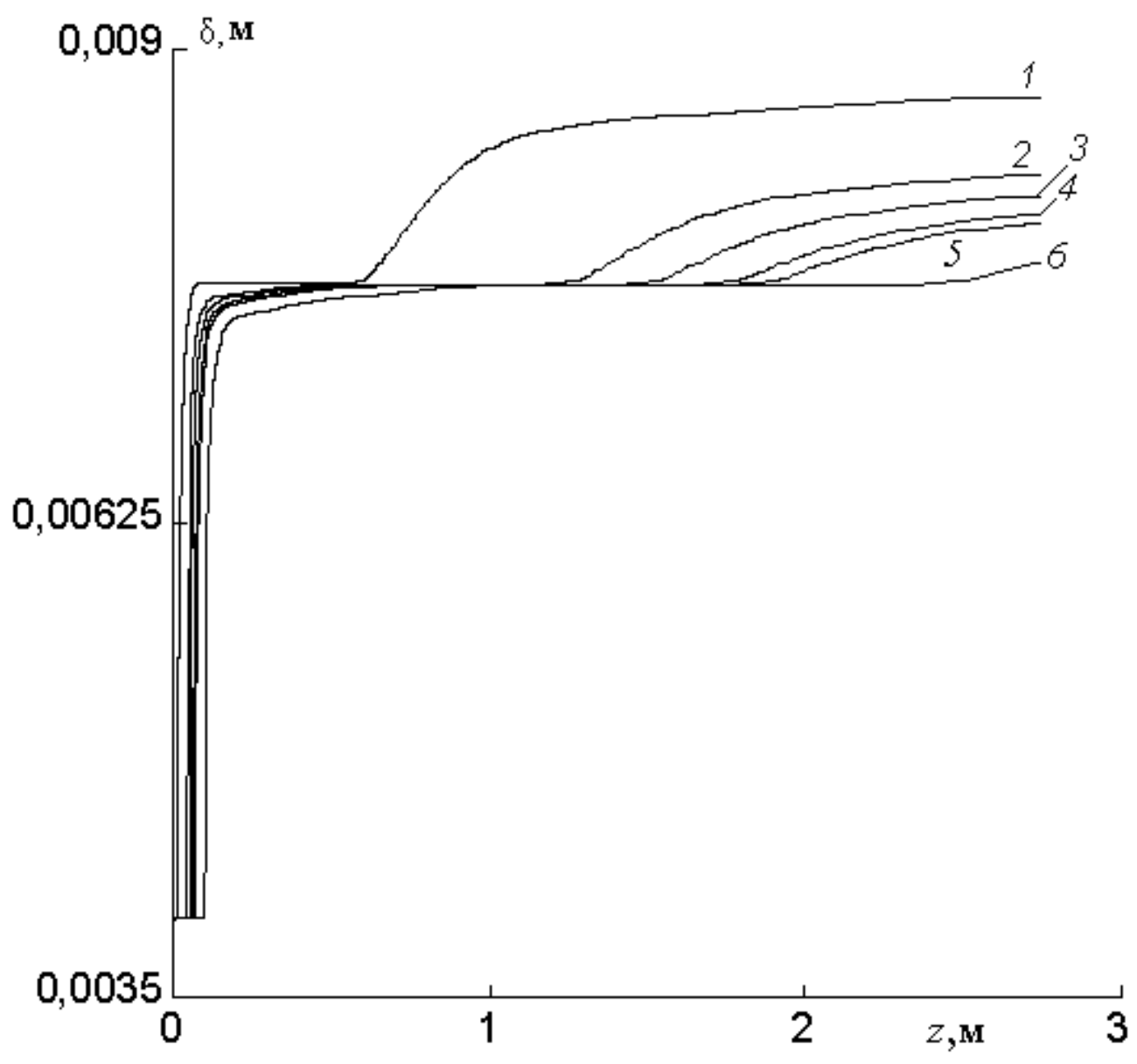

Рис. 5. Распределение диаметра частиц по высоте неподвижного слоя в зависимости от времени (обозначения те же, что на рис. 1)

Fig. 5. Particle diameter distribution over the height of the fixed bed depending on time (notations are the same as in Fig. 1)

Интенсивная конверсия коксозольных частиц в рассматриваемом интервале приводит к резкому уменьшению размера дробленки с $\delta=4,36$ мм до минимального диаметра частиц $\delta_{\text {ash }}=3,96$ мм, состоящих из золы (рис. 5, кривая 2). Полученный таким образом инертный материал формирует шлаковую подушку, которая защищает колосники от перегрева.

Во втором интервале (окислительновосстановительная область реагирования) 0,039 м $<z<0,0704$ м, где объемная доля $\mathrm{O}_{2}$ падает до $1 \%$, теплопоглощение эндотермических реакций превышает тепловыделение экзо- термических реакций. По этой причине температура частиц и содержание водяного пара в газе снижаются до $843{ }^{\circ} \mathrm{C}$ и $32 \%$, объемные доли $\mathrm{CO}_{2}, \mathrm{CO}$ и $\mathrm{H}_{2}$ продолжают возрастать и достигают величин $19,3 \%, 17,2 \%$ и $30,4 \%$, соответственно, а диаметр частиц уменьшается с 7,33 мм до 4,36 мм. Следует отметить, что окислительный диапазон характеризуется отсутствием летучих веществ в угольных частицах, так как скорость убывания пиролизных газов по высоте слоя значительно выше, чем скорость перемещения указанного интервала (рис. 26, кривая 2). 


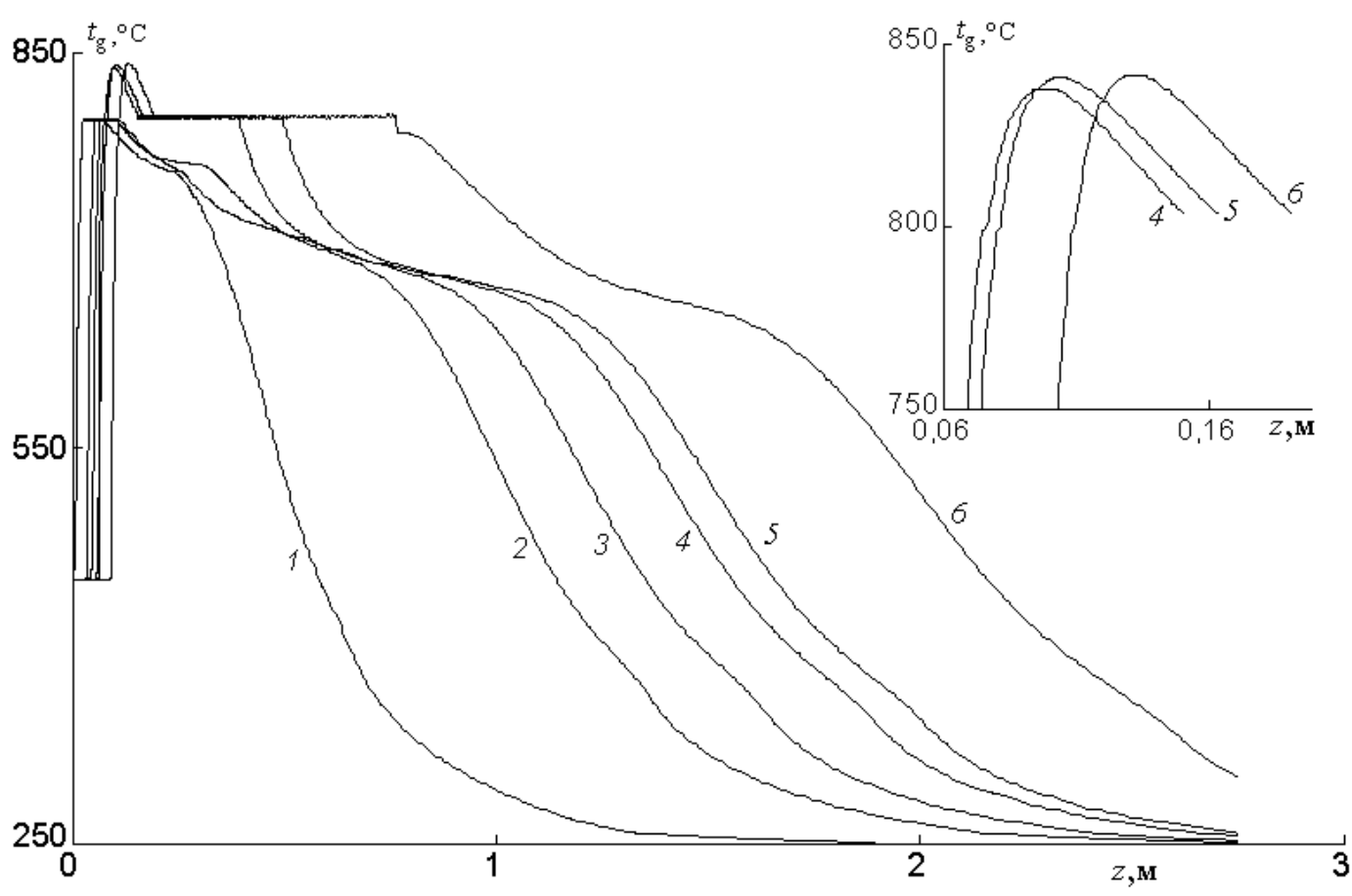

Рис. 6. Распределение температуры газа по высоте неподвижного слоя в зависимости от времени (обозначения те же, что на рис. 1)

Fig. 6. Gas temperature distribution over the height of the fixed bed depending on time (notations are the same as in Fig. 1)

Из рис. 1 и 6 (кривые 4) видно, что функции $t_{\mathrm{p}}(\tau, z)$ и $t_{\mathrm{g}}(\tau, z)$ подобны, однако максимум кривой $t_{\mathrm{g}}(\tau, z)$, формирующийся за счет межфазного конвективного теплообмена и тепловыделения химических реакций $\mathrm{CO}+0,5 \mathrm{O}_{2}=\mathrm{CO}_{2}$ и $\mathrm{H}_{2}+0,5 \mathrm{O}_{2}=\mathrm{H}_{2} \mathrm{O}$, сдвинут вверх по вертикальной оси на 36,5 мм относительно максимума зависимости $t_{\mathrm{p}}(\tau, z)$.

В бескислородной восстановительной зоне 0,0704 м $<z<1,25$ м, где температура коксозольных частиц и объемная доля водяного пара уменьшаются до $403{ }^{\circ} \mathrm{C}$ и $15,6 \%$, функции $R_{\mathrm{CO}_{2}}(\tau, z)$ и $R_{\mathrm{H}_{2}}(\tau$, z) достигают своих максимальных значений 26,6 \% и $42,6 \%$, соответственно, в то время как кривая $R_{\text {СО }}(\tau, z)$ убывает (рис. 1 , рис. 3 , рис. 4 , кривые 2 ). Такое поведение зависимостей $R_{\mathrm{CO}_{2}}(\tau, z), R_{\mathrm{H}_{2}}(\tau, z)$ и $R_{\mathrm{CO}}(\tau, z)$ связано с протеканием химических реакций $\mathrm{C}+\mathrm{CO}_{2}=2 \mathrm{CO}, \quad \mathrm{C}+\mathrm{H}_{2} \mathrm{O}=\mathrm{CO}+\mathrm{H}_{2} \quad$ и $\mathrm{CO}+\mathrm{H}_{2} \mathrm{O} \rightarrow \mathrm{CO}_{2}+\mathrm{H}_{2}$. Здесь генерация $\mathrm{CO}$, обусловленная гетерогенными реакциями, оказывается меньше ее диссипации из-за протекания гомогенной реакции водяного сдвига, благодаря чему зависимость $R_{\text {СО }}(\tau, z)$ убывает до величины $14,6 \%$.
В отличие от режима газификации, приведенного в [1], где отсутствуют пиролизные газы в рассматриваемой области реагирования, здесь присутствует незначительное количество летучих веществ $V=0-0,64 \%$ (рис. 2 в, кривая 2).

В зоне сухой перегонки 1,25 м $<z<2,75$ м происходит нагрев высушенной дробленки до температуры $251-403{ }^{\circ} \mathrm{C}$ (рис. 1, кривая 2) за счет межфазного конвективного теплообмена и радиационно-кондуктивного теплопереноса твердой фазы, что обеспечивает интенсивный выход пиролизных газов из угольных частиц.

Как отмечалось в работе [1], летучие вещества шубаркольского каменного угля могут быть представлены в следующем виде: $\mathrm{CH}_{3,147} \mathrm{O}_{0,5625} \rightarrow 0,09132 \mathrm{CO}+0,0581 \mathrm{CO}_{2}+0,5042 \mathrm{CH}_{4}$ $+0,05783 \mathrm{C}_{6} \mathrm{H}_{6}+0,03655 \mathrm{H}_{2}+0,3549 \mathrm{H}_{2} \mathrm{O}$. Отсюда видно, что содержание метана и водяного пара значительно больше, чем диоксида углерода, окиси углерода и водорода. Поэтому при смешении потоков компонентов пиролизного и синтетического газа, выходящего из бескислородной восстановительной области реагирования, происходит уменьшение величин $R_{\mathrm{CO}}, R_{\mathrm{H}_{2}}, R_{\mathrm{CO}_{2}}$ и 
возрастание значений $R_{\mathrm{H}_{2} \mathrm{O}}, R_{\mathrm{CH}_{4}}$ и $R_{\mathrm{C}_{6} \mathrm{H}_{6}}$ (рис. массу): $\quad R_{\mathrm{CO}}=15 \%, \quad R_{\mathrm{H}_{2}}=37 \%, \quad R_{\mathrm{CO}_{2}}=25 \%$, 3 , рис. 4 , рис. 7 , кривые 2). В зоне сухой перегонки наблюдается уменьшение диаметра частиц с 8,3 мм до 7,64 мм за счет выхода летучих веществ (рис. 5 , кривая 2).

В рассматриваемом временном интервале $0<$ $\tau<360$ с состав генераторного газа на выходе из реактора изменяется за счет уменьшения высоты зоны сухой перегонки. При $\tau=160$ с (на сухую

$R_{\mathrm{CH}_{4}}=21 \%$ и $R_{\mathrm{C}_{6} \mathrm{H}_{6}}=2,4 \% ; \tau=260$ c: $R_{\mathrm{CO}}=16,4 \%$, $R_{\mathrm{H}_{2}}=44,6 \%, \quad R_{\mathrm{CO}_{2}}=27,6 \%, \quad R_{\mathrm{CH}_{4}}=10,1 \% \quad$ и $R_{\mathrm{C}_{6} \mathrm{H}_{6}}=1,16 \%$. Расчетный состав газа при $\tau=260$ с хорошо согласуется с литературными данными, приведенными в [2]: $R_{\mathrm{CO}}=12-21 \%, \quad R_{\mathrm{H}_{2}}=37-$ $41 \%, R_{\mathrm{CO}_{2}}=27-34 \%, R_{\mathrm{CH}_{4}}=10-13,5 \%$.
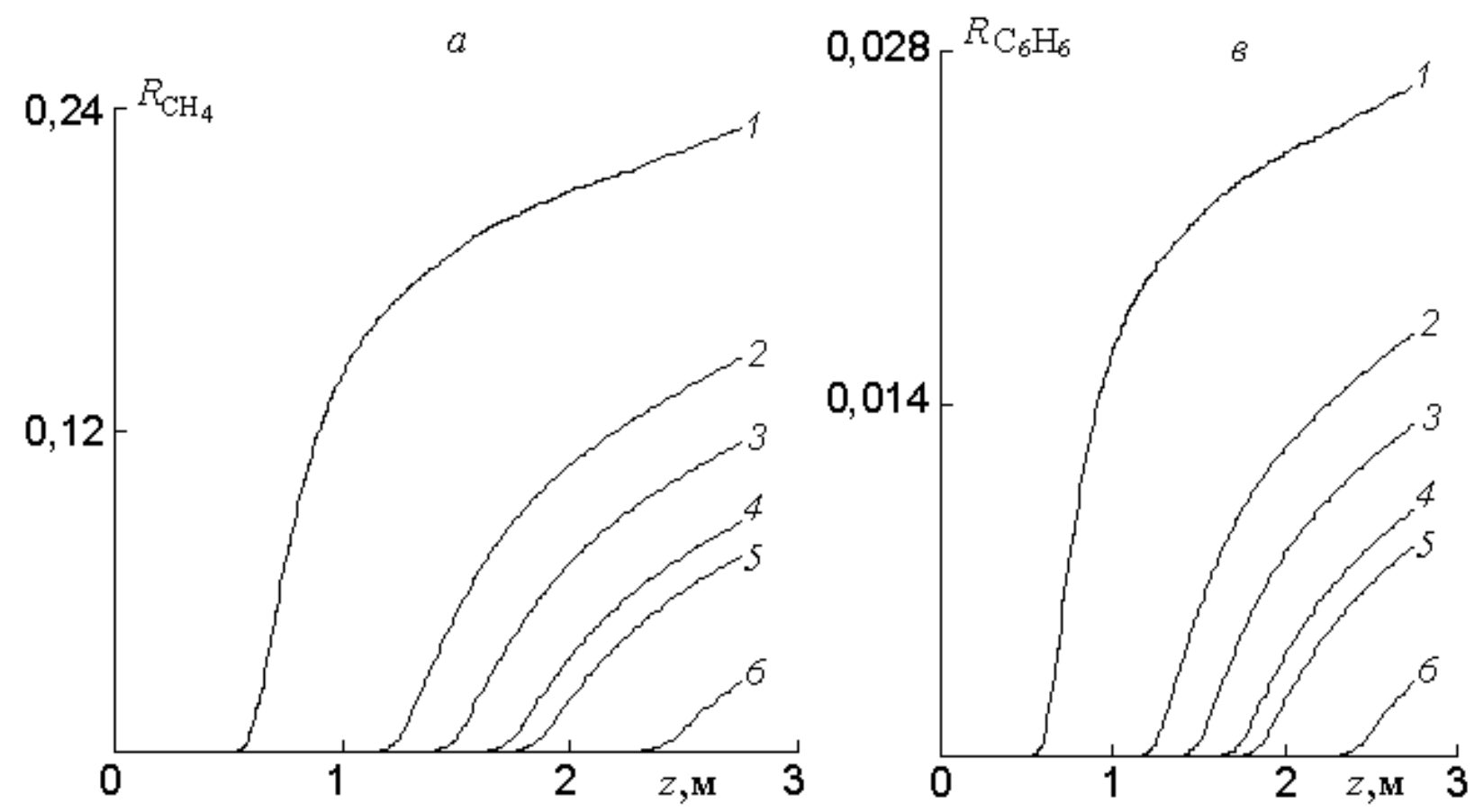

Рис. 7. Распределение объемных долей компонентов газа СН4 (a) и С6 $\mathrm{C}_{6}$ (в) по высоте неподвижного слоя в зависимости от времени (обозначения те же, что на рис. 1)

Fig. 7. Distribution of volume fractions of gas components $\mathrm{CH}_{4}(a)$ and $\mathrm{C}_{6} \mathrm{H}_{6}(\boldsymbol{b})$ over the height of the fixed bed depending on time (notations are the same as in Fig. 1)

Выводы. 1. При организации режима парокислородной газификации шубаркольского каменного угля с твердым шлакоудалением при отношении $\mathrm{H}_{2} \mathrm{O} / \mathrm{O}_{2}=72 / 28$ и $t_{\mathrm{p}}<1000^{\circ} \mathrm{C}$ получается генераторный газ $\left(\tau=260\right.$ с: $R_{\mathrm{CO}}=16,4 \%$, $R_{\mathrm{H}_{2}}=44,6 \%, \quad R_{\mathrm{CO}_{2}}=27,6 \%, \quad R_{\mathrm{CH}_{4}}=10,1 \% \quad$ и $R_{\mathrm{C}_{6} \mathrm{H}_{6}}=1,16 \%$ ), калорийность которого значительно ниже, чем при жидком шлакоудалении $\left(\tau=280 \mathrm{c}: R_{\mathrm{CO}}=65 \%, R_{\mathrm{H}_{2}}=25,6 \%, R_{\mathrm{CO}_{2}}=3,8 \%\right.$, $R_{\mathrm{CH}_{4}}=5 \%$ и $R_{\mathrm{C}_{6} \mathrm{H}_{6}}=0,57 \%$ ) из-за большого содержания балласта $\mathrm{CO}_{2}$.
2. Для устранения перегрева колосниковой решетки из-за низкой высоты шлаковой подушки, обусловленной малой зольностью шубаркольского каменного угля $\mathrm{A}^{\mathrm{r}}=3-9 \%$, в исходное топливо рекомендуется добавлять отработанную золу, что позволяет повысить высоту защитного инертного слоя.

3. Результаты расчетов состава генераторного газа хорошо согласуются с литературными данными Gräbner M. [2].

4. Бескислородная восстановительная зона в процессе газификации шубаркольского каменного угля при отношении $\mathrm{H}_{2} \mathrm{O} / \mathrm{O}_{2}=45 / 55$ [1] явля- 
ется малоэффективной из-за низких значений объемного содержания водяного пара в газовой смеси $R_{\mathrm{H}_{2} \mathrm{O}}=1,36-4,7 \%$, в отличие от рассматриваемого режима $\left(\mathrm{H}_{2} \mathrm{O} / \mathrm{O}_{2}=72 / 28\right)-R_{\mathrm{H}_{2} \mathrm{O}}=15,6-32 \%$, где указанный диапазон реагирования играет существенную роль в термохимическом процессе.

1. Рохман Б.Б. Двумерная модель процесса газификации твердого топлива в неподвижном слое под давлением. 1. Исследование конверсии шубаркольского каменного угля в парокислородной смеси при отношении массовых долей $\mathrm{H}_{2} \mathrm{O} / \mathrm{O}_{2}=45 / 55$. Відновлювана енергетика. 2019. № 1. С. 61-71.

2. Gräbner M. Industrial Coal Gasification Technologies Covering Baseline and High Ash Coal. Wiley. 2014. 384 p.

\section{REFERENCES}

1. Rokhman B.B. Dvumernaya model processa gazifikacii tverdogo topliva $v$ nepodvizhnom sloe pod davleniem. 1. Issledovanie konversii shubarkolskogo kamennogo uglya $\mathrm{v}$ parokislorodnoj smesi pri otnoshenii massovyh dolej $\mathrm{H} 2 \mathrm{O} / \mathrm{O} 2=45 / 55$. [Two-dimensional model of the solid fuel gasification in a fixed bed under presser. 1. Investigation of Shubarkol coal conversion in a steam-oxygen mixture with the mass part of $\mathrm{H} 2 \mathrm{O} / \mathrm{O} 2=45 / 55]$. Vidnovluvana energetika. 2019. No. 1. Pp. 6171. [in Russian].

2. Gräbner M. Industrial Coal Gasification Technologies Covering Baseline and High Ash Coal. Wiley. 2014. 384 p. [in English].

\author{
ДВОВИМІРНА МОДЕЛЬ ПРОЦЕСУ ГАЗИФІКАЦІЇ \\ ТВЕРДОГО ПАЛИВА В НЕРУХОМОМУ ШАРІ ПЫД \\ ТИСКОМ. 2. ЧИСЛОВІ РЕЗУЛЬТАТИ \\ ТЕРМОХІМІЧНОЇ ПЕРЕРОБКИ \\ ШУБАРКОЛЬСЬКОГО КАМ'ЯНОГО ВУГІЛЛЯ ПРИ \\ СПІВВІДНОШЕННІ МАСОВИХ ЧАСТОК $\mathrm{H}_{2} \mathrm{O} / \mathrm{O}_{2}=72 / 28$
}

Б.Б. Рохман, докт. техн. наук

Інститут вугольних енерготехнологій НАН України 04070 м. Київ, вул. Андріївська, 19

3 використанням розробленої двовимірної моделі, наведеноі в першій частині иієї роботи, яка включає в себе міжфазовий конвективний теплообмін, радіаційно-кондуктивний теплоперенос твердої фази, променистий і кондуктивний теплообмін нерухомого шару зі стінкою реактора, гетерогенні і гомогенні хімічні реакиії, сили тяжіння $і$ аеродинамічного опору чисельно досліджений нестаціонарний процес газифікачії иубаркольского кам'яного довгополуменевого вугілля в парокисневій суміші під тиском 3 МПа в нерухомому шарі з твердим шлаковидаленням при відношенні масових часток газових компонентів $\mathrm{H}_{2} \mathrm{O} / \mathrm{O}_{2}=72 / 28$. Показано, що: 1) в розглянутому режимі температура коксозольних частинок не перевищуе $1000{ }^{\circ} \mathrm{C}$ за рахунок превалювання тепловиділення екзотермічних реакиій $\mathrm{C}+\mathrm{O}_{2}=\mathrm{CO}_{2}$, $\mathrm{C}+0,5 \mathrm{O}_{2}=\mathrm{CO}, \mathrm{CO}+0,5 \mathrm{O}_{2}=\mathrm{CO}_{2}$ i $\mathrm{H}_{2}+0,5 \mathrm{O}_{2}=\mathrm{H}_{2} \mathrm{O}$ над теплопоглинанням ендотермічних реакиій $\mathrm{C}+\mathrm{CO}_{2}=2 \mathrm{CO} \quad i$ $\mathrm{C}+\mathrm{H}_{2} \mathrm{O}=\mathrm{CO}+\mathrm{H}_{2}$ через велику концентрачію водяної пари в газовій суміші. Тому генераторний газ за своїми характеристиками калорійності і якості (в момент часу $\tau=260 \mathrm{c}$ (за об'ємом): $\mathrm{CO}=16,4 \%, \mathrm{H}_{2}=44,6 \%, \mathrm{CO}_{2}=27,6 \%, \mathrm{CH}_{4}=10,1 \% \mathrm{i}$ $\left.\mathrm{C}_{6} \mathrm{H}_{6}=1,16 \%\right)$ значно поступається синтетичному газу, отриманому при відношенні масових часток газових компонентів $\mathrm{H}_{2} \mathrm{O} / \mathrm{O}_{2}=40 / 60 \quad\left(\tau=280 \mathrm{c}: \mathrm{CO}=65 \%, \mathrm{H}_{2}=25,6 \%\right.$, $\mathrm{CO}_{2}=3,8 \%, \mathrm{CH}_{4}=5 \%$ i $\mathrm{C}_{6} \mathrm{H}_{6}=0,57 \%$ ) [1]; 2) для усунення перегріву колосників через низьку висоту шлакової подушки, обумовлену малою зольністю вугілля 3-9\%, у вихідне паливо рекомендується додавати відпрачьовану золу, що дозволить підвищити висоту захисного інертного шару; 3) розрахунковий склад синтетичного газу при $\tau=260$ с добре узгоджується з літературними даними, наведеними в [2]: $\mathrm{CO}=12-21 \%, \mathrm{H}_{2}=37-41 \%$, $\mathrm{CO}_{2}=27-34 \%$ i $\mathrm{CH}_{4}=10-13,5 \%$.

Ключеві слова: нерухомий шар, вугілля, теплопроводність, парокиснева газифікація, кондуктивний, радиаџіоний, температура 